NBER WORKING PAPER SERIES

POVERTY TRAPS AND THE SOCIAL PROTECTION PARADOX

\author{
Munenobu Ikegami \\ Michael R. Carter \\ Christopher B. Barrett \\ Sarah A. Janzen \\ Working Paper 22714 \\ http://www.nber.org/papers/w22714 \\ NATIONAL BUREAU OF ECONOMIC RESEARCH \\ 1050 Massachusetts Avenue \\ Cambridge, MA 02138 \\ October 2016
}

We thank John Hoddinott, Valerie Kozel, Felix Naschold and seminar audiences at the International Food Policy Research Institute, Namur, Purdue, Wageningen, Wisconsin and the World Bank for helpful comments on earlier versions of this work. Generous financial support was provided by the Social Protection Division of the World Bank and by a grant from the USAID Office of Poverty Reduction to the BASIS Assets and Market Assets Innovation Lab. The ideas expressed are the responsibility of the authors and should not be attributed to either sponsoring organization, nor to the National Bureau of Economic Research.

NBER working papers are circulated for discussion and comment purposes. They have not been peer-reviewed or been subject to the review by the NBER Board of Directors that accompanies official NBER publications.

(C) 2016 by Munenobu Ikegami, Michael R. Carter, Christopher B. Barrett, and Sarah A. Janzen. All rights reserved. Short sections of text, not to exceed two paragraphs, may be quoted without explicit permission provided that full credit, including $\odot$ notice, is given to the source. 
Poverty Traps and the Social Protection Paradox

Munenobu Ikegami, Michael R. Carter, Christopher B. Barrett, and Sarah A. Janzen

NBER Working Paper No. 22714

October 2016

JEL No. D91,I32,O12

\begin{abstract}
$\underline{\text { ABSTRACT }}$
Progressively targeted cash transfers remain the dominant policy response to chronic poverty in developing countries. But are there alternative social protection policies that might have larger poverty impacts over time for the same public expenditure? To explore this question, this paper develops a dynamic stochastic model of of consumption and asset accumulation by households that confront a non-convex production technology and face missing financial markets. The model demonstrates that a hybrid social protection policy, which devotes resources to funding "state of the world contingent transfers" (SWCTs) to vulnerable, but non-poor households in the wake of negative shocks, can result in lower rates of poverty in the medium term than does a conventional cash transfer policy. We also explore the prospects for using subsidized index insurance as a way to implement SWCTs and find that an insurance-based hybrid policy can result in lower total public expenditures than a conventional cash transfer social protection program.
\end{abstract}

Munenobu Ikegami

International Livestock Research Institute

Nairobi, Kenya

m.ikegami@cgiar.org

Michael R. Carter

Department of Agricultural and

Resource Economics

University of California, Davis

One Shields Avenue

Davis, CA 95616

and NBER

mrcarter@ucdavis.edu
Christopher B. Barrett

Dyson School of Applied Economics and Management

Cornell University

Ithaca, NY

cbb2@cornell.edu

Sarah A. Janzen

Department of Economics

Montana State University

Bozeman, MN 59717; USA

sarah.janzen@montana.edu 


\section{Poverty Traps and the Social Protection Paradox}

Cash transfer programs, progressively targeted at the poorest, have become a predominant policy for addressing chronic poverty in developing countries. While pioneered by middle income developing countries (notably Mexico, South Africa and Brazil), cash transfer programs have spread more broadly across the developing world, including the risk-prone pastoral regions of Northern Kenya whose economic reality underwrites the analysis in this paper. ${ }^{1}$ There is ample evidence that cash transfers break the liquidity constraints that Loury (1981) argues propagate poverty inter-generationally by limiting parents' health and education investment in their children. However, there is much more modest evidence that these programs enhance the earned incomes of recipient households and impact their living standards once the cash transfers come to an end, despite their theoretical potential to do so. ${ }^{2}$ Indeed policymakers in Latin America now confront the conundrum of former cash transfer recipients who revert to their pre-transfer living standards once their transfer eligibility ends. In northern Kenya, the Hurrell and Sabates-Wheeler (2013b) impact evaluation of the Hunger Safety Net Program (HSNP) cash transfer scheme found that while transfers allowed recipient households to economically tread water even as their untreated neighbors sunk under the weight of continuing shocks, it did nothing to help recipient households craft a pathway from poverty. Similar to Latin American countries, Kenya is now looking to augment its HSNP cash transfer program with a "poverty graduation program."

The apparently weak impact of cash transfer programs on the upward mobility of poor households in at least the medium run has particular salience in risky regions. If cash transfers do little to promote upward mobility in general, their impact on poverty dynamics may be further blunted in risky environments because they do not protect the assets of

\footnotetext{
${ }^{1}$ With the region receiving "emergency" food aid year after year, the Kenyan government in 2009 created a social protection scheme, the Hunger Safety Nets Program (HSNP), built around bi-monthly cash transfers targeted at the region's chronically poor and indigent. By regularizing progressively-targeted assistance, HSNP had hoped to put households on a pathway from poverty by enabling asset accumulation and sustained investment in child health and education so as to avert future chronic poverty arising due to economic disability (see the discussion in the Hurrell and Sabates-Wheeler (2013a)).

${ }^{2}$ The Gertler et al. (2012) study of Mexico's Progresa program finds notable investment and income effects from a purely cash transfer program. The Bastagli et al. (2016) review study finds more modest evidence of such effects, unless specific efforts were made by implementers to support planning, investment and business development. In a similar spirit, the six country studies contained Maldonado et al., eds (2016) find some evidence that the potential impacts of cash transfers on earned income are when cash transfers are paired with ancillary business development programs targeted at cash transfer recipients.

${ }^{3}$ The current generation of graduation programs take their inspiration from BRAC's ultra-poor program that recognizes that more than liquidity increments to reduce poverty. Such programs involve a mix of cash transfers, financial education, confidence building and coaching, and culminate with a discrete asset transfer. Banerjee et al. (2015) summarize evaluations of graduation programs that span both middle and low income countries.
} 
the non-poor who are vulnerable to falling into poverty. This omission has two potential effects. First, conventional cash transfers do not stem the downflow of the poor into poverty that is driven by shocks (Krishna (2006)). Second, by not protecting the assets of the vulnerable non-poor, cash transfers in turn do little to enhance the investment incentives of the already poor. ${ }^{4}$ Given these two effects, the population of future poor may grow and either (a) benefits to households shrink if the social protection budget is fixed; or, (b) the social protection budget balloons to keep pace with the growing number of poor households.

These observations raise the question as to whether an alternative social protection scheme might be more effective at reducing the extent and depth of poverty compared to the purely progressive targeting rules of standard cash transfer programs. Using a dynamic stochastic programming model meant to capture key features of a risky rural landscape like that of Northern Kenya, this paper explores the poverty reduction potential of a hybrid social protection system that combines means-tested cash transfers with "state of the world contingent transfers" (SWCTs) made to the vulnerable, non-poor in the wake of negative shocks.

Our findings include what we call the paradox of social protection. Under the assumption that transfers are unanticipated (i.e., households do not alter their accumulation strategies in anticipation of social protection benefits), we show that compared to a standard, progressively targeted scheme, a hybrid policy that diverts some the social protection budget to the vulnerable non-poor results in a lower levels of poverty in the medium term, although poverty rates are higher in the short term. Conventional cash transfer programs thus implicitly make an intertemporal tradeoff between the well-being of the poor today versus their well-being in the future. The hybrid program of course creates the mirror intertemporal tradeoff.

We then relax the assumption that transfers are unanticipated and explore the impacts of hybrid social protection when the contingent transfers are anticipated. We show first that anticipation crowds in additional accumulation by the poor, who are incentivized by the fact that SWCTs will protect their assets should they invest and advance to the ranks of vulnerable non-poor. This ex ante accumulation effect might be termed positive moral hazard as it is induced risk taking that lessens the overall rate of poverty. At the same time, when SWCTs are precisely targeted at the vulnerable as in our model, a new equilibrium appears. Specifically, a subset of agents accumulate only to the point where they are eligible for SWCTs, but not beyond. This new equilibrium reflects what might be termed as negative moral hazard, as those at this equilibrium make choices that increase the probability of insurance-like contingent social protection payments.

\footnotetext{
${ }^{4}$ Indeed, if anything, it might be expected that means-tested cash transfers would discourage accumulation as successful accumulation could lead to loss of benefits.
} 
Given the tradeoffs, expense and complexities associated with SWCTs and hybrid social protection, we then ask whether the impacts of an SWCT can be achieved with an insurance contract which is co-funded by the government and by the vulnerable non-poor. Rather than holding the social protection budget fixed, we instead ask how much budget is needed over time to fully close the poverty gap for all poor households and to pay for the government insurance subsidy that is offered to all poor and vulnerable non-poor households under the hybrid scheme. Drawing on companion work that models the dynamically optimal demand for insurance (Janzen et al. (2016)), we show that present value of the required government expenditure stream is lower under the hybrid insurance scheme than it would be under a conventional cash transfer scheme targeted only at the poor. This cost saving is realized without any tradeoff between the well-being of the poor in the present and the future.

The remainder of the paper proceeds as follows. Section 1 presents a dynamic stochastic model of household consumption and asset accumulation in which households enjoy heterogeneous endowments of productive skill. Section 2 then uses this model to analyze a stylized model of a village economy comprised of 300 households distributed randomly over the ability-initial asset space that defines the intertemporal choice model. As a baseline for later analysis of alternative policy regimes, we use dynamic programming methods to simulate the stylized economy over a sixty year time horizon, tracking the evolution of growth, poverty and a new measure of "unnecessary deprivation."

Section 3 then explores the impact of alternative social protection schemes, one that targets transfers in a purely progressive fashion, and another in which the available budget is targeted according to a triage protocol that prioritizes transfers to households that are vulnerable to slipping into chronic poverty over transfers to already poor households. In this section, we assume that households do not anticipate transfers. It is here where the paradox of social protection emerges. By preventing collapse into poverty by agents vulnerable to asset shocks, the triage scheme ultimately reduces the extent of poverty and leads to greater transfers to and higher welfare for poor households in later years.

Section 4 then relaxes the assumption that transfers are unanticipated and explores what happens when agents fully anticipate contingent transfers provided to the vulnerable under the triage scheme. We show that anticipation of these transfers has both positive and negative effects. Finally we show that implementing the contingent transfers as a partially subsidized insurance contract (with co-pays required of beneficiaries) eliminates the negative while preserving the positive effects of contingent protection. Section 5 concludes the paper. 


\section{Assets, Ability, Risk and the Multiple Dimensions of Chronic Poverty}

Azariadis and Stachurski (2005) define a poverty trap as a "self-reinforcing mechanism which causes poverty to persist." A robust theoretical literature has identified a variety of such mechanisms that may operate at either the macro level-meaning that an entire country or region is trapped in poverty-or at the micro level-meaning that a subset of individuals become trapped in chronic poverty even as others escape (Barrett and Carter, 2013, Kraay and McKenzie, 2014, and Ghatak, 2015 provide recent review papers). In this paper, we explore the implications of a micro poverty trap mechanism for the design of social protection programs, employing a variant of what Barrett and Carter (2013) call the "multiple financial market failure" poverty trap model. This model can generate multiple equilibria in the sense that a given individual may end up at the high or the low equilibrium depending on initial conditions and stochastic realizations.

The semi-arid pastoral region of Northern Kenya, which motivates this work, is an area of widespread chronic poverty. Multiple studies, using different data sets, have found evidence of bifurcated asset dynamics in this region, with households above a critical level tending to a high equilibrium and those below it tending to a low level (Barrett et al. (2006); Lybbert et al. (2004); McPeak and Barrett (2001); Santos and Barrett (2011, 2016)). ${ }^{5}$ To explore how social protection might work in this environment, we build on the Buera (2009) non-stochastic model of asset accumulation with two production technologies under credit constraints and heterogeneous agent ability. ${ }^{6}$ We extend Buera's model by adding asset shocks to allow for the importance of both ex ante awareness of risk and the ex post experience of shocks as key determinants of poverty dynamics (Elbers and Gunning (2005)).

We show that multiple poverty trap mechanisms emerge in this setting. Low ability households are innately poor, as they never find the high-return technology attractive and thus they endure low incomes indefinitely. Meanwhile, intermediate ability households dramatically change asset accumulation and production choices in response to ex ante asset risk

\footnotetext{
${ }^{5}$ Note, these findings do not generalize globally. Broad-based empirical evidence of poverty traps has been mixed (Subramanian and Deaton, 1996; Kraay and McKenzie, 2014), although Kraay and McKenzie (2014) conclude that the evidence for the existence of structural poverty traps is strongest in rural remote regions like the arid and semi-arid lands of East Africa. As Barrett and Carter (2013) note, there is a tendency to sometimes conflate the failure to find a multiple equilibrium poverty trap with the non-existence of poverty traps. Poverty traps can of course be single equilibrium, as in Nashold (2013). For a particularly interesting analysis of the emergence of a multiple equilibrium from a single equilibrium structure, see Kwak and Smith (2013).

${ }^{6}$ Related previous papers include Becker and Tomes (1979), Loury (1981), Banerjee and Newman (1991, 1993), Galor and Zeira (1993), Ray and Streufert (1993), Aghion and Bolton (1997), Piketty (1997), Carter and Zimmerman (2000), Ghatak, Morelli and Sjostrom (2001) and Ghatak and Jiang (2002).
} 
and ex post realization of asset shocks. This cohort faces a multiple equilibrium poverty trap of the sort on which the literature has long focused. Finally, there is a high ability group that may start poor but will inevitably take up the high-return technology and graduate out of poverty and remain non-poor (in expectation) indefinitely.

\subsection{A Model of Asset Dynamics and Heterogeneous Ability}

Consider an economy in which each individual $j$ is endowed with a level of innate ability $\left(\alpha_{j}\right)$ as well as an initial stock of capital $\left(k_{j 0}\right)$. Preferences are unrelated to the individual's innate ability. In what follows, we treat $\alpha_{j}$ as fixed. We conceptualize the agents in this economy as adults and $\alpha_{j}$ as capturing the effectively immutable physical stature, cognitive development and educational attainment with which they enter adulthood and thus the economy. This approach obviously ignores the origins and evolution of such innate ability. Carter and Janzen (2015) generalize the specification here and allow each household's human capital to evolve endogenously over time through a stochastic process in which ability regresses to the mean level unless compromised by nutritional shortfalls.

Exploring the multigenerational extension to the present model, by endogenizing $\alpha_{j}$, seems a promising topic for future research, not least of which because it would directly address the economic growth and poverty reduction effects of early childhood nutrition, health and education interventions. In this paper, however, we set those questions aside in order to concentrate on exploring social protection policy design in the presence of poverty traps.

Each period the individual has to choose between two alternative technologies for generating income. Both technologies are capital using and skill-sensitive (i.e., for both technologies, more able people can produce more than less able people). One technology (the "high "technology) is subject to a fixed cost, $E$, such that the technology is not worth using at low amounts of capital. Specifically, we assume that income, $f$, for individual $j$ in period $t$ is given by

$$
f\left(\alpha_{j}, k_{j t}\right)=\alpha_{j} \max \left[f_{H}\left(k_{j t}\right), f_{L}\left(k_{j t}\right)\right]
$$

where $f_{L}\left(\alpha_{j}, k_{j t}\right)=\alpha k_{j t}^{\gamma_{L}}, f_{H}\left(\alpha_{j}, k_{j t}\right)=\alpha k_{j t}^{\gamma_{H}}-E, E>0$ and $0<\gamma_{L}<\gamma_{H}<1$. We denote as $\hat{k}(\alpha)$ as the value of capital where it becomes worthwhile to switch to the more productive technology (i.e., $\left.\widehat{k}\left(\alpha_{j}\right)=\left\{k \mid f_{L}\left(\alpha_{j}, k\right)=f_{H}\left(\alpha_{j}, k\right)\right\}\right){ }^{7}$

If an individual had access to only one technology, she or he would accumulate capital

\footnotetext{
${ }^{7}$ By construction, this formulation favors adoption of the high technology by assuming away information problems and all other obstacles to adoption other than financing. These simplifications eliminate inessential factors that would reinforce the effect that are generated here under full information.
} 
up to a unique steady state values $k_{L}^{*}\left(\alpha_{j}\right)$ for the low technology or $k_{H}^{*}\left(\alpha_{j}\right)$ for the high technology. The key question is then what happens when the individual has access to both technologies. In particular, will an individual whose initial capital stock is below $\widehat{k}\left(\alpha_{j}\right)$ gravitate toward the high or the low technology and, relatedly, toward the higher or lower income level associated with the different technologies? ${ }^{8}$ Consider the case of an individual who begins life with $k_{L}^{*}\left(\alpha_{j}\right)<k_{j 0}<\widehat{k}\left(\alpha_{j}\right)$. Note that because this individual is beyond the low level steady state, incremental returns to further investment are low and discourage further investment. Borrowing constraints, and limited income, make it impossible for the individual to discretely jump over the region of low returns. Will this individual optimally accumulate assets over time, and ending up at $k_{H}^{*}\left(\alpha_{j}\right)$ and a non-poor standard of living? Alternatively, will the individual settle into a poor standard of living with capital stock $k_{L}^{*}\left(\alpha_{j}\right)$ ? More formally, is there an initial asset threshold, which we will denote $\widetilde{k}\left(\alpha_{j}\right)$, below which individuals stay at the low equilibrium (remaining chronically poor), and above which she or he will move to the high equilibrium (eventually becoming non-poor)?

We analyze this question with a dynamic model of consumption and investment choice. We rule out borrowing and hence consumption every period can be no more than available wealth, or what Deaton (1991) calls cash on hand:

$$
c_{j t} \leq k_{j t}+f\left(\alpha_{j}, k_{j t}\right)
$$

The household's stock of accumulated capital evolves over time according to the following rule:

$$
k_{j t+1}=\left(k_{j t}+f\left(\alpha_{j}, k_{j t}\right)-c_{t}\right)\left(\theta_{t+1}-\delta\right) .
$$

where $\delta$ is the natural asset depreciation rate and $\theta_{t} \in[0,1]$ is a random asset shock realized at the beginning of every period $t$. Note that $\theta=1$ indicates that there is no shock, whereas $\theta<1$ indicates an unfavorable shock that destroys some fraction of assets. While in principal $\theta>1$ might be allowed, such events seem unlikely and we will restrict the analysis to the case where only negative shocks are possible. The cumulative density function of $\theta_{t}$ is denoted by $\Omega(\cdot)$ and we assume that every household knows $\Omega(\cdot)$.

Assembling these pieces, we can write the decision-maker's intertemporal choice problem as:

\footnotetext{
${ }^{8}$ This question was first (?) explored bySkiba (1978) that with a non-convex production technology, bifurcated accumulation strategy could occur around a critical minimum asset level.
} 


$$
\max _{c_{j t}} \quad E_{\theta} \sum_{t=0}^{\infty} \beta^{t} u\left(c_{j t}\right)
$$

subject to:

$$
\begin{aligned}
& c_{j t} \leq k_{j t}+f\left(k_{j t}\right) \\
& f\left(\alpha_{j}, k_{j t}\right)=\alpha_{j} \max \left[f_{H}\left(k_{j t}\right), f_{L}\left(k_{j t}\right)\right] \\
& k_{j t+1}=\left(k_{j t}+f\left(k_{j t}\right)-c_{j t}\right)\left(\theta_{j t+1}-\delta\right) \\
& k_{j t} \geq 0
\end{aligned}
$$

where $\mathrm{E}_{\theta}$ is expectation taken over the distribution of the random shock $\theta, \beta$ is the time discount factor, and $u(\cdot)$ is the utility function defined over consumption $c_{t}$ and has the usual properties. Denote the investment rule in the presence of asset shocks as $i^{*}\left(k_{t} \mid \alpha, \Omega\right){ }^{9}$

\subsection{The Micawber Frontier and the Two Dimensions of Chronic Poverty}

As in Skiba (1978) and Buera (2009), this model identifies a critical asset level, denoted $\widetilde{k}(\alpha)$, around which dynamic behavior bifurcates. An individual with ability level $\alpha_{j}$ will attempt to accumulate the assets needed to reach the high technology equilibrium if she enjoys capital stock $k_{j \tau}>\widetilde{k}\left(\alpha_{j}\right)$. Otherwise, she will only pursue the low technology, accumulating the modest stock of capital that it requires. Note that this frontier, a generalization of what Carter and Barrett (2006) call the Micawber Threshold, divides those who have the wealth needed to accumulate from those who do not. ${ }^{10}$ We label $\widetilde{k}(\alpha)$ the Micawber Frontier.

The two graphs in Figure 1, created through numerical analysis of the dynamic programming model 1, present the Micawber Frontier under the parameterization reported in Appendix 1. ${ }^{11}$ Along the horizontal axes are innate ability or skill levels, ranging from least to most able. The vertical axes measures the stock of productive assets. Figure 1a graphs the

\footnotetext{
${ }^{9}$ More precisely, $i^{*}\left(k_{t} \mid \alpha, \Omega\right)$ is the policy function of the following Bellman equation:

$$
\begin{aligned}
& V\left(k_{t}\right) \equiv \max _{i_{t}}\left\{u\left(f\left(\alpha, k_{t}\right)-i_{t}\right)+\beta E\left[V\left(k_{t+1} \mid k_{t}, i_{t}\right)\right]\right\} \\
& \text { where } E\left[V\left(k_{t+1} \mid k_{t}, i_{t}\right)\right]=\int V\left(\theta_{t}\left[i_{t}+(1-\delta) k_{t}\right]\right) d \Omega\left(\theta_{t}\right)
\end{aligned}
$$

${ }^{10}$ Skiba (1978) less poetically calls the equivalent in his model a critial cutoff point.

${ }^{11}$ Buera (2009)provides a formal proof for his non-stochastic model. Appendix 1 details the parameterization used to implement the numerical analysis of the stochastic model discussed in the remainder of the
} paper. 
Figure 1: The Micawber Frontier and Chronic Poverty

(a) Probability of Chronic Poverty (\%)

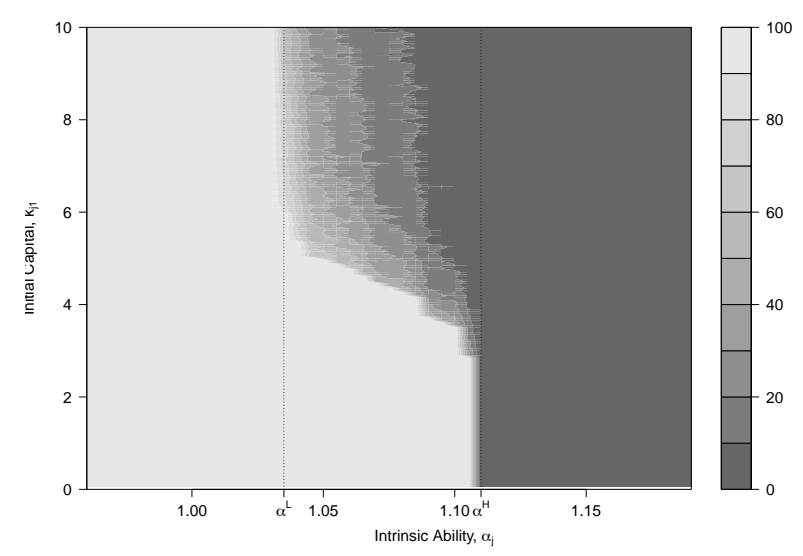

(b) Risk and the Micawber Frontier

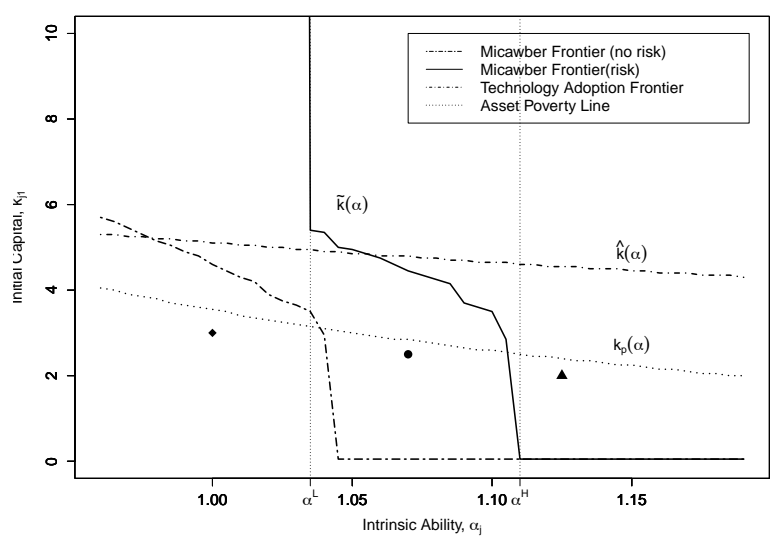

probability that a household occupying each initial endowment position will end up chronically poor, i.e., at the low level equilibrium. Notice that households on west/southwest side of the figure approach the low level equilibrium with probability one, indicating that for these endowment positions it is not worthwhile to even attempt the accumulation of the assets required to reach the high equilibrium. As shown in Figure 1b, we define the Micawber frontier as the locus of skill and assets where the household behaving optimally according to Model 1 where the probability of escaping chronic becomes strictly positive. The solid curve in the figure graphs this locus. Comparing across the two graphs in Figure 1, we can see that for endowment positions far enough east and north of the Frontier, the probability of escaping chronic poverty is essentially one. For middle ability households in the multi-toned band just north and east of the Micawber Frontier, the probabilities of escape are modest.

To ease discussion and link it to more conventional poverty analysis, Figure 1 also includes an "asset poverty line," the dashed downward sloping line, denoted $k_{p}(\alpha)$. For each ability level, this asset poverty line indicates the stock of assets the individual must have in order to produce a living standard exactly equal to a money metric poverty line, $y_{p}$. We define $y_{p}$ as the level of income that a reference middle ability person $\left(\alpha_{m}=1.12{ }^{* *}\right.$ check this number**) would produce were she in steady state equilibrium at the low technology $\left(y_{p}=\right.$ $f\left(\alpha_{m}, k_{L}^{*}\left(\alpha_{m}\right)\right)$. This assumption is of course arbitrary, ${ }^{12}$ but it has the advantage of rendering most individuals poor unless they craft a pathway to the high technology. This is desirable

\footnotetext{
${ }^{12}$ Standard poverty lines are of course inherently arbitrary. In contrast, the Micawber Frontier has a behavioral foundation, as well as strong behavioral implications, as Hoddinott (2006) discusses, and can be thought of as a dynamic asset poverty line (Carter and Barrett 2006, Carter and Ikegami 2007).
} 
in our stylized model as it creates a strong linkage between improved technology adoption, income and poverty measures.

Note that the Micawber Frontier has a behavioral foundation and thus differs from from the asset poverty line, which is based on a standard (and therefore somewhat arbitrary) income poverty line. ${ }^{13}$ Those agents whose initial ability-asset endowments place them above the Micawber Frontier but beneath the asset poverty line will be initially poor. With the positive probability illustrated in Figure 1a, these individuals will prove to only transitorily poor as they attempt to accumulate their way out of poverty.

By contrast, those whose initial endowments situates them beneath the Micawber Frontier but above the asset poverty line will not be poor initially, but will steadily eat into their asset holdings and will eventually become poor. These movements represent structural transitions across the poverty line. There can also be stochastic movements around the asset poverty line among the subpopulation that finds itself above the Micawber Frontier. For those individuals, small asset shocks may temporarily leave them beneath the asset poverty line without driving them off their growth path toward the high equilibrium. Of course, individuals could find themselves above (below) both the Micawber Frontier and the asset poverty line, in which case they would be always non-poor (poor). This simple depiction of the Micawber Frontier and the asset poverty line thereby captures the full range of conventional static and dynamic poverty measures. ${ }^{14}$

As illustrated in Figure 1, the numerical analysis identifies three distinct regions in the space of ability and initial asset holdings. Irrespective of their capital endowment, high skill individuals with $\alpha_{j}>\alpha^{H}$ will always move toward the high equilibrium as $\widetilde{k}\left(\alpha_{j}\right)=0 \forall \alpha_{j}>$ $\alpha^{H}$. When they reach the technology shift asset threshold $\widehat{k}\left(\alpha_{j}\right)$ they will optimally switch to the higher technology. Irrespective of their starting position, these upwardly mobile agents steadily converge to the steady state asset value for the high technology. They may be poor over some extended period as they move toward their steady state value, but eventually they should become non-poor by virtue of the optimal accumulation behavior induced by their high ability endowment. Such individuals do not face a poverty trap.

In contrast, those with an innate ability level below the critical level $\alpha^{L}$ will never move toward the high technology irrespective of their initial asset endowment. This critical skill level defines a region of intrinsic chronic poverty, made up of individuals who lack the ability to achieve a non-poor standard of living in their existing economic context. ${ }^{15}$ These indi-

\footnotetext{
${ }^{13}$ As discussed by Carter and Ikegami (2009), this characteristic of the Micawber Frontier makes it an interesting candidate as the base for chronic poverty measures.

${ }^{14}$ See Carter and Barrett (2006) for a discussion of distinct generations of poverty analysis that encompass these different ideas.

${ }^{15} \mathrm{CPRC}$ (2004) gives examples of individuals who suffer such fundamental disabilities.
} 
viduals face a unique, low-level equilibrium, a very different sort of poverty trap than is confronted by the third and final set of agents.

Those in the intermediate skill group with $\alpha^{L}<\alpha_{j}<\alpha^{H}$ have positive but finite values

$\widetilde{k}\left(\alpha_{j}\right)$. If sufficiently well-endowed with assets $\left(k_{j 0}>\widetilde{k}(\alpha)\right)$, these intermediate ability individuals will attempt to accumulate additional assets over time, and will with some strictly positive probability adopt the high technology and eventually reach a non-poor standard of living. However, if these same intermediate skill individuals begin with assets below $\widetilde{k}(\alpha)$, they will no longer find the high equilibrium attainable and will settle into a low standard of living. Like those in the region of intrinsic chronic poverty, intermediate ability individuals initially endowed with less than $\widetilde{k}(\alpha)$ will be chronically poor. Unlike the intrinsically chronically poor, the chronic poverty of the intermediate skilled individuals is needless or unnecessary deprivation in the sense that they could be helped to lift themselves out of poverty with appropriate social protection policies, as we discuss below. The total number of chronically poor in any society will thus depend on the distribution of households across the ability-wealth space.

Finally note that while some authors (e.g., Barrett and Carter (2013) and Kray and McKenize (2014)) often distinguish between single equilibrium poverty trap models, multiple equilibrium poverty trap models and models without poverty traps, our model here admits the coexistence of all three possibilities in a single structure.

\subsection{The Ex-post and Ex-ante Effects of Asset Shocks}

The Micawber Frontier is a function of the economic environment in which individuals find themselves. In particular, the distribution of the stochastic term $\theta$ fundamentally shapes investment behavior. We now explore the impact of ex ante risk and ex post shocks on investment and the long-term evolution of poverty.

The ex post effect of realized shocks comes about simply because negative events may destroy assets, knocking people off their expected path of accumulation. For upwardly mobile individuals, such shocks may delay their arrival at the upper level equilibrium, or knock them down from it, necessitating a period of additional savings and asset reaccumulation. But it does not set them on a different accumulation path. Similarly, realized shocks have no long-term effect on the equilibrium toward which the low ability, intrinsically chronically poor gravitate.

In contrast, the ex post consequences of shocks can be rather more severe for households of intermediate ability. Consider the case of a household that is initially slightly above the Micawber Frontier. A shock that knocks it below that frontier will banish the household 
into the ranks of the chronically poor as in the wake of the shock, the household will alter its strategy and move toward the low equilibrium (divesting itself of assets).

While these ex post effects of shocks are important, the anticipation that they might take place would be expected to generate a "sense of insecurity, of potential harm people must feel wary of - something bad can happen and "spell ruin," as Calvo and Dercon (2009) put it. Numerical analysis of the model shows that this sense of impending ruin indeed discourages forward-looking households from making the sacrifices necessary to reach the high equilibrium. The Micawber Frontier shifts to the southwest once asset risk is removed, as shown in Figure 1b. The dashed curve is the Micawber Frontier in the absence of risk. The boundaries marking the critical skill levels at which households move between the different accumulation regimes also shift out, meaning more intrinsically upwardly mobile households and fewer intrinsically chronically poor households when we eliminate the ex ante effects of risk.

The most dramatic effects of risk are seen by considering a household whose skill and capital endowments place it between the two frontiers. Consider a household whose skill and initial asset endowments are represented by the solid circle in the middle of Figure 1. Absent the risk of asset shocks, such a household would strive for the upper equilibrium and eventually escape poverty. In the presence of risk, such a household would abandon this accumulation strategy as futile and settle into a low level, chronically poor standard of living. In the face of asset risk, the extraordinary sacrifice of consumption required to try to reach the high equilibrium is no longer worthwhile, and the household will optimally pursue the low level, poverty trap equilibrium. By contrast, the shift has no significant behavioral effect on either intrinsically chronically poor households (represented by the solid diamond on the left side of Figure 1) or intrinsically upwardly mobile households (the solid triangle on the right side of Figure 1).

To explore the differential effects of risk and shocks on these different sub-populations, Carter and Ikegami (2009) used the dynamic choice model above and simulated the income streams it generates in three distinct settings:

- A non-stochastic economy in which agents repeatedly apply the optimal investment rule, $i_{n}^{*}\left(k_{t} \mid \alpha_{j}\right)^{16}$,

\footnotetext{
${ }^{16}$ The subscript $n$ denotes this non-stochastic world and $i_{n}^{*}\left(k_{t} \mid \alpha\right)$ is policy function of the following Bellman equation:

$$
\begin{array}{r}
V_{n r}\left(k_{t}\right) \equiv \max _{i_{t}}\left\{u\left(f\left(\alpha, k_{t}\right)-i_{t}\right)+\beta V_{n r}\left(k_{t+1} \mid k_{t}, i_{t}\right)\right\} \\
=\max _{i_{t}}\left\{u\left(f\left(\alpha, k_{t}\right)-i_{t}\right)+\beta V_{n r}\left(i_{t}+(1-\delta) k_{t}\right)\right\}
\end{array}
$$
}


- An economy characterized by risk without realized shocks in which agents follow the risk-adjusted optimal accumulation rule, $i^{*}\left(k_{t} \mid \alpha_{j}, \Omega\right)$, but never actually experience shocks (a scenario that allows us to isolate the ex ante effects of risk); and,

- A fully stochastic economy, meaning that individuals not only follow the risk-adjusted optimal investment rule but each period they are subject to a random asset shock generated in accordance with the probability structure $\Omega$.

These simulations show that for the intrinsically chronically poor (low $\left.\alpha_{j}\right)$ and the upwardly mobile (high $\alpha_{j}$ ) groups, the effects of risk are relatively modest and attributable almost entirely to the disruptive, ex post effects of asset shocks. By contrast, for the intermediate ability group, the ex ante behavioral (i.e., investment disincentive) effects of uninsured risk account for most of the welfare effects due to asset stochasticity. These effects are also large in magnitude. While the discounted income streams for the other two groups fall only 5-10 percent in the fully stochastic scenario, the drop is approximately 25 percent for the intermediate ability group, with roughly 90 percent of the losses due to the ex ante risk effect exclusively. ${ }^{17}$ The difference arises because while risk slightly reduces the desired steady state capital stock for low and high ability agents, mainly it forces them to regularly rebuild assets in order to reattain the desired steady state capital stock. In sharp contrast, intermediate ability agents may fundamentally shift their investment strategy in the presence of risk, eschewing any attempt at trying to reach the high-level equilibrium open to them, creating added avoidable chronic poverty.

Among other things, these simulations show that in the presence of critical asset thresholds, risk takes on particular importance for those individuals subject to multiple equilibria. Social protection policies could in principal generate large returns for such individuals, as the next two sections describe. Furthermore, this response to risk adds an important twist to the moral hazard that naturally results from any policy that attempts to reduce risk exposure, as we discuss in section 4 below.

\section{Accumulation and Poverty Dynamics Absent Social Pro- tection}

The analysis in the prior section showed that both the anticipation and experience of economic shocks have a fundamental effect on behavior and welfare in the presence of poverty traps, expanding the portion of the endowment space from which people do not escape

\footnotetext{
${ }^{17}$ Details on these simulation results are available from the authors by request.
} 
poverty through their own efforts. This observation suggests that social protection policies have a fundamental role to play in stimulating poverty reduction and economic growth. But how should social protection be designed in a world with multiple sources of poverty traps? As a first step towards answering this question, this section uses the model of individual decisionmaking developed above as the basis for analyzing accumulation, growth and poverty in a stylized economy lacking any social protection policies. Sections 3 and 4 will then take a careful look at the impact of alternative social protection schemes on this economy.

\subsection{The Stylized Economy and Measures of Performance}

Consider now an economy comprised of agents whose livelihood choices are described by inter-temporal maximization problem 1. To keep things simple, we will assume that all shocks are idiosyncratic and that prices in the economy are unaffected by shocks and by individuals' decisions. While these assumptions are clearly at odds with the real world, they permit us in the first instance to clarify basic principles and tradeoffs in the design of social protection policies. ${ }^{18}$

For purposes of the numerical analysis, we assume that there are 300 agents, each described by a skill and initial capital stock pair. We allocated agents along the skill continuum, with $25 \%$ each in the intrinsically chronically poor and upwardly mobile ranges, and half the agents in the intermediate ability range where endowments matter to their accumulation and welfare trajectories. Each agent was then assigned a random initial capital stock drawn from a uniform distribution over the zero to ten range. While in any existing economy we would expect there to be a correlation between skill and observed capital stock, this random assignment of capital creates an experimental environment in which to study asset dynamics under alternative social protection schemes.

The diagram in the northwest corner of Figure 2 shows the initial distribution of ability and wealth in this stylized economy. Each symbol on the graph represents the initial position of an individual agent or household dynasty. The solid line is the Micawber Threshold under the stochastic environment, while the dashed line is again the asset poverty line. The other graphs in the figure-to be discussed below-show the evolution of endowment positions under under alternative social protection policies.

While we can simply focus on the trajectories of agents given their initial endowment positions, we also employ a set of summary measures to track the performance of the stylized

\footnotetext{
${ }^{18}$ When shocks are correlated across households, asset and other prices will begin to covary with household income. The implications of this covariance can be important as Carter, Little, Mogues and Negatu (2007) discuss empirically in the case of Ethiopia. Zimmerman and Carter (2003) theoretically examine the implications of such asset price covariance, showing that it can create another type of poverty trap.
} 
Figure 2: Asset Evolution with and without Social Protection

Initial Distribution

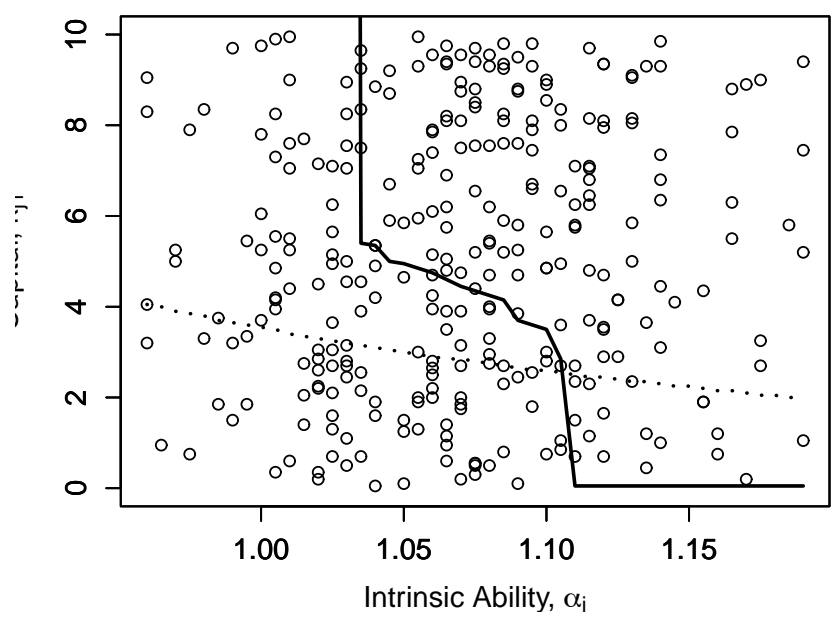

Year 50 Needs-based

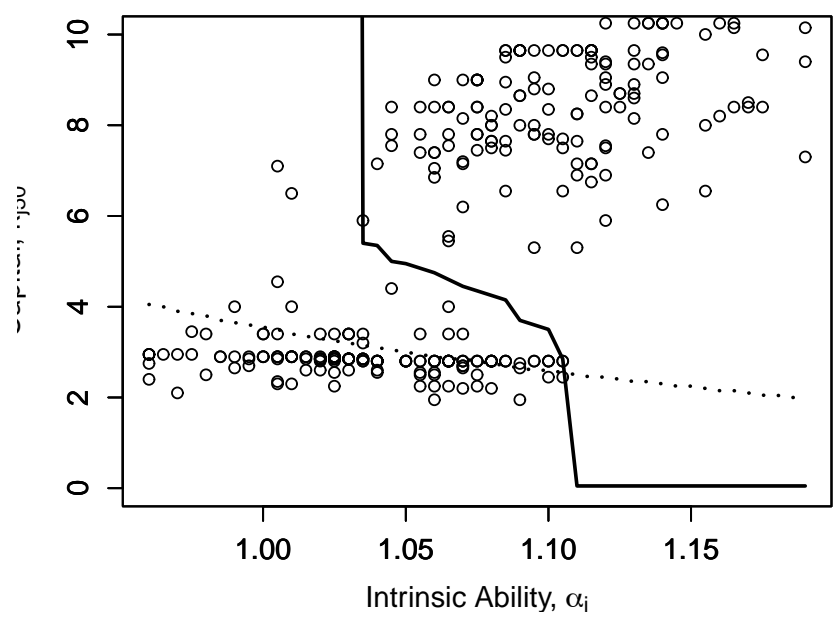

Year 50 Autarchy

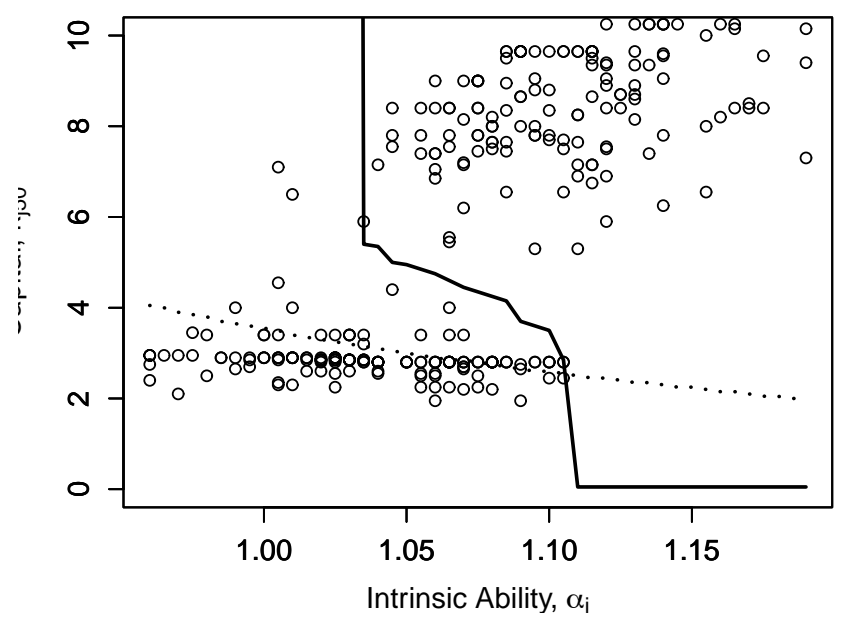

Year 50 Triage

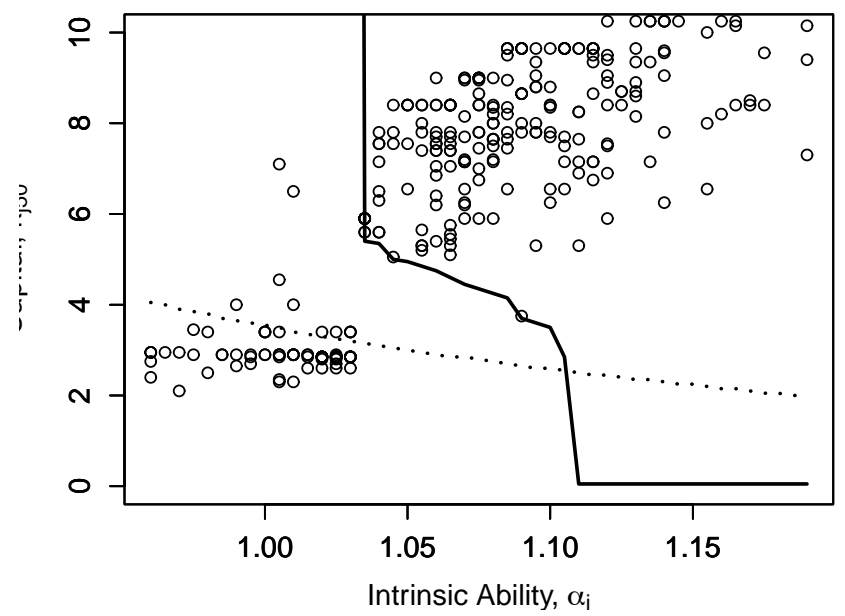


economy under alternative social protection regimes: ${ }^{19}$

1. GNI defined simply as the sum of the incomes of the 300 agents. Note that this measure will evolve over time based on capital accumulation (or deaccumulation) as well as the shift of households between the low and high productivity regimes.

2. Standard static poverty measures based on the Foster-Greer-Thorbecke (FGT) family of measures:

$$
P_{\gamma}^{y}=\frac{1}{n} \sum_{y_{j}<y_{p}}\left(\frac{y_{p}-y_{j}}{y_{p}}\right)^{\gamma}
$$

where $n$ is total number of individuals, $y_{p}$ is income poverty line, $y_{i}$ is individual $j$ 's income, and $\gamma$ is the usual FGT sensitivity parameter. We will specifically focus on the popular headcount $\left(P_{0}^{y}\right)$ and poverty gap $\left(P_{1}^{y}\right)$ measures. As discussed above, we set the poverty line $y_{p}$ at the level of income that a medium skilled individual would produce in steady state if she had access only to the low technology.

3. A novel measure of unnecessary deprivation, $D_{\gamma}^{y}$. This measure resembles the FGT poverty gap measure, in that it continues to focus just on those with current income beneath the income poverty line, $y_{p}$, but with the important refinement that rather than comparing individuals' realized income against $y_{p}$, current income is compared instead against the income level associated with the household's optimal capital stock given its innate skill endowment, $\bar{k}^{*}\left(\alpha_{j}\right)=\max \left\{k_{H}^{*}\left(\alpha_{i}\right), k_{L}^{*}\left(\alpha_{j}\right)\right\}$, if its initial wealth endowment did not constrain equilibrium selection, as it does for some households of intermediate ability. As with the FGT measure, $\gamma$ is a sensitivity parameter, with $\gamma=0$ offering a headcount of those who suffer unnecessary deprivation, $\gamma=1$ measuring the money metric gap between potential and current well-being, and $\gamma>1$ placing greater weight on larger underperformance relative to potential. In our subsequent calculations, we report only the $\gamma=1$ variant. Thus, we define $D_{\gamma}^{y}$ as

$$
D_{\gamma}^{y}=\frac{1}{n} \sum_{\substack{y_{j}<y_{p} \\ y_{j}<f\left(\alpha_{j}, \bar{k}^{*}\left(\alpha_{j}\right)\right)}}\left(\frac{f\left(\alpha_{i}, \bar{k}^{*}\left(\alpha_{j}\right)\right)-y_{j}}{f\left(\alpha_{i}, \bar{k}^{*}\left(\alpha_{j}\right)\right)}\right)^{\gamma}
$$

This measure captures unnecessary deprivation, in that chronically poor individuals who achieve their steady state income level (i.e., $\left.f\left(\alpha_{j}, \bar{k}^{*}\left(\alpha_{j}\right)\right)=y_{j}\right)$ realize their full potential

\footnotetext{
${ }^{19}$ In work not reported here, we also analyzed the impacts of the different policies using a conventional Benthamite social welfare function as well as the dynamic poverty measures suggested by Calvo and Dercon (2007). The qualitative story told by these measures is similar to that which can be gleaned from the measures discussed here.
} 
and have zero weight in this measure, as do the non-poor (for whom $y_{j}>y_{p}$ ). Instead, the "potential gap" captures mainly those of intermediate skill who are trapped in a low-level equilibrium or those who are presently far from their long-run equilibrium (e.g., upwardly mobile individuals with very low initial endowments). This measure is impractical in empirical work, since it relies on an estimate of steady-state capital holdings conditional on unobservable ability; it is nonetheless helpful as a conceptual tool for distinguishing unnecessary poverty from that which is unavoidable given individuals' immutable endowments and the economic environment in which they operate.

These economic core measures permit us to track over time both the social costs (foregone output and unexploited technological opportunities) and the human costs (low standards of living and unnecessary deprivation) of poverty traps.

\subsection{Baseline Case of No Social Protection}

The northeast panel of Figure 2 shows the asset distribution after 50 years of simulated history for our stylized economy. As can be seen, the asset distribution (which was originally randomly distributed independently of the ability distribution) has bifurcated, with a strong positive correlation between innate ability and wealth. One set of individuals has comfortably settled above the Micawber Frontier at the high technology steady state. The other group is at the low level steady state, below the asset poverty line. There are quite a few poor individuals in the middle ability group whose potential to reach the high equilibrium has been blocked by their low initial asset levels, or realized) asset shocks, that locked them below the Micawber Frontier.

With no exogenous technical change or growth in productive inputs to stimulate growth and modest investment incentives for a large portion of the population, GNI in this baseline economy is relatively stagnant over time as reflected in the "autarchy" line in the northwest quadrant of Figure 2. This reflects the fact that the positive accumulation and associated productivity gains of those above the Micawber Frontier is offset by the lost potential - and wealth deaccumulation and productivity decline - of many of those trapped below it. The decline among some sub-populations is manifest in the disadoption of the high technology, use of which falls from roughly $60 \%$ to only $40 \%$ of the population. Further reflection of this economic bifurcation is found in the increasing levels of poverty, measured both as a poverty headcount (northeast quadrant) as well as by the poverty gap indicator (southwest quadrant) and our unnecessary deprivation measure (southeast quadrant). Income inequality (not shown) declines modestly over the first decade of the simulations, then increases above the initial level by year 25 as households converge on their $\alpha$-conditional long-run equilibria. 
Figure 3: Economic Evolution under Alternative Social Protection Policies
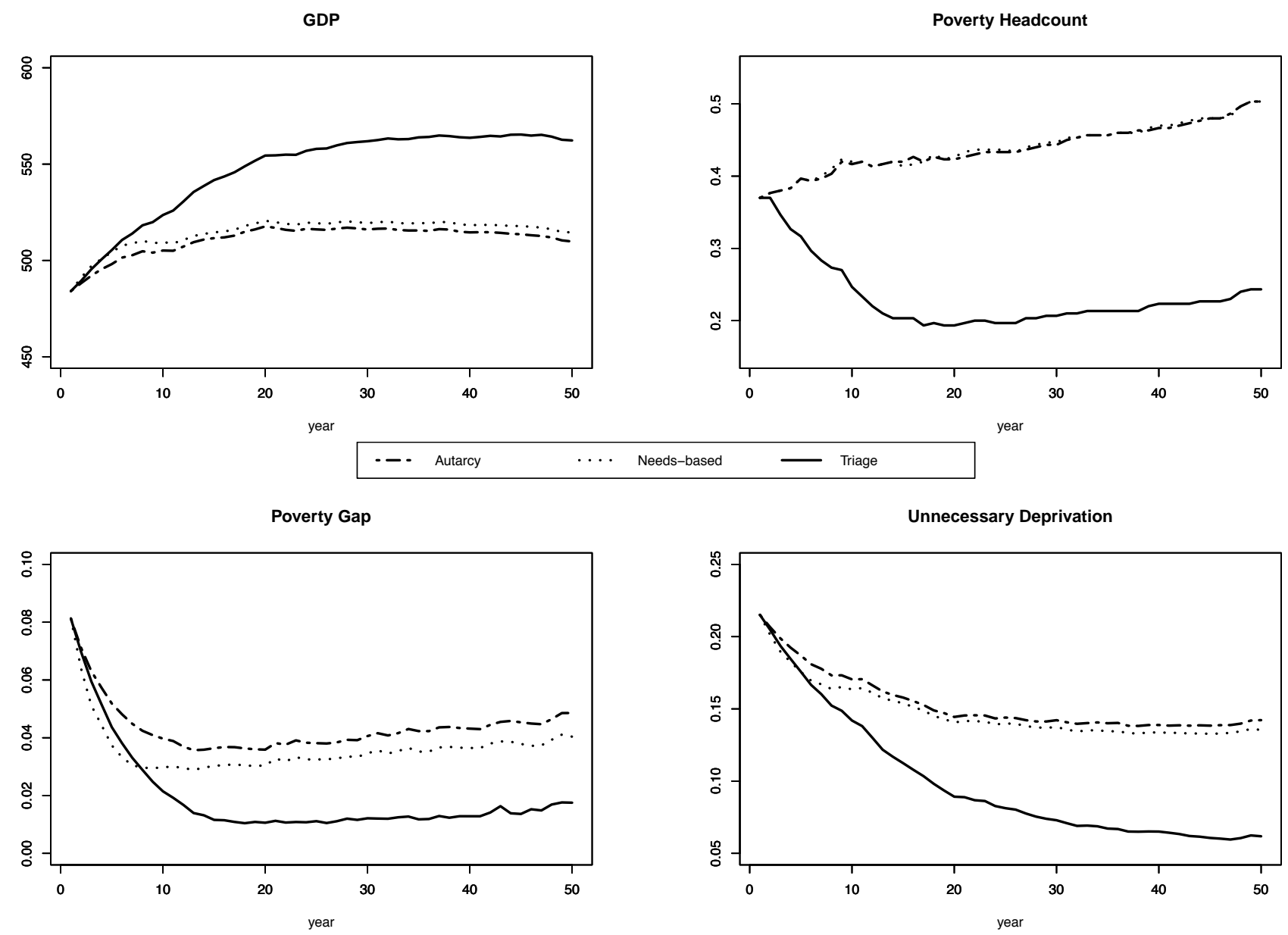

The lackluster performance of the base case poverty trap economy illustrates both the human and aggregate economic costs of poverty traps. The next sections consider alternative policy regimes that might lead to better outcomes.

\section{Poverty Dynamics and the Targeting of Unanticipated Social Protection}

This section examines the impact of reactive food aid or unanticipated social protection policies on the stylized economy studied in the prior section. The label unanticipated signals that these policies are implemented ex post of shocks and we assume away agents' anticipation of the resulting transfers and the behavioral response that would follow from such anticipa- 
tion. This oversimplification is made simply to help understand more clearly how poverty dynamics shift in response to different sorts of social protection policies. In particular, we seek to illustrate clearly the value of addressing the purely ex post effects of asset shocks, even if agents do not expect transfers. Section 4 relaxes the assumption that households fail to anticipate and respond to social protection policies.

For all alternatives, we assume that the social protection agency ${ }^{20}$ has access to an annual income stream or budget of that amounts to $2.5 \%$ of initial GNI. ${ }^{21}$ This amount was chosen because it is insufficient to lift all initially poor individuals above the poverty line, though it is enough to substantially close the poverty gap. We further assume that the social protection agency has access to full information, including household ability and asset holdings, realized shocks and knowledge of the production technology. While these are strong assumptions, using them to explore targeting of this limited assistance budget helps further illustrate the workings of the multiple poverty trap economy.

\subsection{Poverty and Aid Traps under Progressive, Means-tested Cash Transfers}

Under the progressively-targeted or needs-based scenario, the agency uses its budget only for progressively targeted, humanitarian/cash transfers. After each production cycle, it calculates the total poverty shortfall for the economy, $S=\sum_{y_{j}<y_{p}}\left(y_{p}-y_{j}\right)$. If the available budget exceeds the shortfall $\left(\frac{B}{S}>1\right)$, then all poor individuals are given transfers to increase their income to the level of the poverty line. If $\frac{B}{S}<1$, then each poor individual is given transfers that move them to an income level equal to $\frac{B}{S} y_{p}$. Note that this targeting methods makes the largest transfers to the least well-off. Once individuals receive the transfer, they make their consumption versus investment decision according to maximization of problem 1 above and assume that future transfers will never occur. Section 4 relaxes this strong assumption, but for now it helps to understand the different effects of alternative designs.

The impact of this needs-based assistance regime on asset distribution can be seen in the southwest diagram in Figure 2. The figure is quite similar to that under autarchy (the northeast panel), except that asset levels are somewhat higher for those below the poverty line, especially among lower ability persons, reflecting a transfer rule based on realized income levels. Turning to Figure 3, we see that the poverty headcount and unnecessary deprivation

\footnotetext{
${ }^{20}$ We use the broad term social protection agency to encompass local or national government as well as non-governmental organizations (NGOs) that might respond to shocks.

${ }^{21}$ We ignore the source of taxation that generates these resources and the associated distortionary effects on the economy. They could be conceptualized as either external resources (brought in by a donor, an NGO or a relief agency), or as domestic tax resources transferred from another sector of the national economy.
} 
measures follow a trajectory nearly identical to that which emerges absent social protection. The FGT(1) poverty gap measure is substantially lower under needs-based assistance than without the assistance, reflecting the added resources introduced into the system exogenously. But we can also see that the FGT(1) steadily rises after year 10 of the simulation. GNI is higher in the economy with needs-based transfer, but purely due to the extra $2.5 \%$ of GNI assumed available each year.

In a world where budgets for transfers are available exogenously (e.g., via unrequited transfers associated with overseas development assistance), progressively-targeted transfers that flow mainly to the chronically poor of low innate ability plainly reduces income and asset poverty, if only because there are added resources in this scenario. However, these transfers do not fundamentally alter the economy's dynamics. Indeed, the troubling irony is that poverty grows in this economy in spite of these transfers as some agents suffer asset shocks that drop them into poverty but then receive insufficient transfers to enable them to climb back out of poverty on their own. Transfer policies that are designed to respond to one poverty trap mechanism-low innate ability-systematically fail to address the other poverty trap in this economy by failing to prevent more people from inadvertently falling into the trap over time.

These results signal what might be termed a relief trap. By failing to stem the flow of intermediate ability individuals below the Micawber Frontier, the fixed humanitarian assistance budget becomes less and less able to meet the needs of those below the poverty line. If the social protection agency (or the international community) were intent on holding poverty at, say, year 10 levels, then increasing fractions of total public expenditures would need to be devoted to aid budgets to accommodate the inflow of the unnecessarily poor who have suffered severe asset shocks and fallen into the basin of attraction of their lowlevel equilibrium. We abstract here from the standard public finance problems of raising revenues, but clearly the growing demands for transfers would have to be met either through increasingly distortionary taxation or through reducing funds available for developing new technologies, building schools and infrastructure, or other interventions (not modeled here) that are aimed at boosting productivity. Poverty traps can thus, in a very direct way, create relief traps for purely progressively targeted social protection programs.

\subsection{Sate of the World Contingent Transfers}

As the prior simulations make clear, in our model asset risk creates an ever increasing amount of unnecessary deprivation that eventually overwhelms the capacity of cash transfers to provide relief. This observation suggests that a social protection scheme targeted at 
the vulnerable in the vicinity of the Micawber Frontier-i.e., a safety net designed to stem the increase in unnecessary poverty-can potentially generate a win-win-win scenario, with higher rates of improved technology adoption and GNI growth, reduced poverty (especially for intermediate ability groups), and less stress on the social protection budget with which it serves those of low innate ability who are intrinsically chronically poor.

To explore this idea, we initially analyze an admittedly harsh "triage" policy regime in which the social protection agency provides transfers to households according to the following rules:

1. The budget, $B$, is first allocated to individuals recently below the Micawber Frontier by negative shocks. Denote these threshold-based transfers as State of the World Contingent Transfers (SWCTs). An individual $j$ is eligible for a SWCT of amount $S W C T_{j}=\tilde{k}\left(\alpha_{j}\right)-\theta_{t}\left[i_{j t}+(1-\delta) k_{j t}\right]$ if $i_{j t}+(1-\delta) k_{j t}>\tilde{k}\left(\alpha_{j}\right)$ and $\theta_{j t}\left[i_{j t}+(1-\right.$ $\left.\delta) k_{j t}\right]<\tilde{k}\left(\alpha_{j}\right)$. In words, if an individual was above the Micawber Frontier prior to the most recent asset shock, but below it afterward, the agency provides a transfer to move the household back to the Micawber Frontier. If the total budget $(S W C T=$ $\sum_{j=1} S W C T_{j}$ ) exceeds the total eligible transfers, then all individuals pushed below the threshold are given an asset transfer to lift them back to it. If the budget is insufficient, then it is allocated first to those closest to the Micawber Frontier so as to minimize the increase in the headcount of needless poverty.

2. If there is any remained budget after step 1 (i.e., if $B>S W C T$ ), then those midability individuals already below the Micawber Frontier (due to low initial inheritance or prior bad luck not stemmed by a $S W C T$ transfer) are given priority for cargo net transfers that lift them over the Micawber Frontier. ${ }^{22}$ Analogous to stage 1, total potential spending on cargo net transfers is calculated (denote this total amount as $C N)$. If $C N>B-S W C T$, then the budget is again prioritized in order to minimize headcount poverty, by first helping the most vulnerable, defined as those closest to the Micawber Frontier.

3. If $B>S W C T+C N$, then the residual budget is allocated according to the progressive or needs-based formulation discussed in the previous sub-section.

Figures 2 and 3 illustrate the results of this assistance regime for our stylized poverty trap economy. The results stand in strong contrast to autarchy and needs-based assistance simulations. As shown in the southeast panel of Figure 3, by year 50, all needless poverty is

\footnotetext{
${ }^{22}$ The term "cargo net" was coined by Barrett (2005) and refers to transfers intended to lift people above - or help people climb over - thresholds at which accumulation dynamics bifurcate, as distinct from safety nets, which prevent people from falling beneath those same thresholds.
} 
eliminated and the headcount of total poverty levels off at $25 \%$, the share of the population that is intrinsically chronically poor by construction. Technology adoption is high, as is GNI (and GNI growth). In the longer-run, this triage approach to development assistance plainly outperforms needs-based assistance by any of these metrics.

However, the southwest diagram in Figure 3 illustrates a core ethical challenge associated with vulnerability-targeted social protection. The FGT(1) poverty gap measure is lower under progressively-targeted cash transfers for the first 8-10 years of the simulation because needs-based assistance flows primarily to the least well-off while the stylized vulnerabilitytargeted policies are aimed at those nearest the Micawber Frontier. Paradoxically, after 8-10 years, those who are poor are better off under VTCT design because it reduces the number of people needing assistance, allowing the fixed social protection budget to provide more generous support to those who inevitably need it. But, prior to that time, individuals who are poor, and especially the poorest, are better off under needs-based targeting. The results for (asset or income) inequality (not shown) are qualitatively similar, with needsbased transfers generating lower inequality in the economy over the first nine years, but threshold-based transfers generating lower inequality over longer horizons. These results underscore the difficult tradeoffs inherent to the design of social protection policy, both over time and across sub-populations of the poor:

- Do we prioritize reducing the depth of poverty for the poor today or the poor tomorrow?

- Do we focus on helping those who, with a bit of assistance, can then pull themselves out of poverty by their bootstraps, or on those who will suffer low living standards in the absence of assistance of indefinite duration?

In the presence of multiple poverty trap mechanisms, these tradeoffs become especially sharp. ${ }^{23}$

\section{Moral Hazard and the Design of Anticipated Social Protection}

The analysis in Section 3 revealed the paradoxes and challenges of social protection in an economy characterized by poverty traps that take several forms. That analysis, however was

\footnotetext{
${ }^{23}$ In additional simulations not reported here, we considered whether these tradeoffs could be mitigated by mixing different kinds of transfers and/or by reallocating budgets intertemporally through borrowing. While these alternatives can reduce the magnitude of the tradeoffs reported here somewhat, they cannot be eliminated entirely. This underscores the unavoidable nature of the targeting tradeoffs in both cross-section (between different sub-populations of the poor and vulnerable) and over time in a multiple poverty trap economy.
} 
incomplete as it assumed that individuals do not anticipate social protection benefits. This lacunae is especially important for state of the world contingent transfers that are targeted at the vulnerable. Such transfers operate as a form of insurance, and as discussed in the introduction above, might be expected to alter ex ante investment incentives for households both above and below the Micawber frontier itself.

In this section we therefore relax the assumption that contingent transfers are unanticipated and consider households' rational response to them. While we could in principle analyze endogenous response to anticipated, progressively-targeted cash transfers, we here limit our attention to anticipated of vulnerability-targeted social protection schemes. ${ }^{24}$

\subsection{Positive and Negative Moral Hazard}

We expect two kinds of household response to safety net transfers. First, since safety net transfers mitigate asset risk, households are willing to accumulate more assets ceteris paribus. This is canonical moral hazard, in that the provision of some insurance induces increased risk taking. ${ }^{25}$ In this model, accumulation of assets subject to stochastic shocks is the only risk-taking behavior available to agents. But asset accumulation is socially desirable in this setting, as it increases productivity and adoption of improved production technologies, increases GNI and reduces poverty. We therefore call this incentive effect "positive moral hazard."

Second, because the safety net transfers are conditional (on pre- and post-shock asset holdings) and given the standard intertemporal tradeoff between current consumption and saving for future consumption, ceteris paribus households have an incentive to satisfy the transfer condition as often as possible so as to receive extra resources. If some external agency or government will insure them against falling into a poverty trap, households do not need to self-insure through asset accumulation to the same degree, thereby creating a disincentive to invest-equivalently, reducing the need for precautionary savings-that runs counter to social objectives. We therefore label this effect "negative moral hazard."

For a middle ability person with $\tilde{k}(\alpha)=5$, Figure 4 a shows expected asset losses as a function of level of capital stock held with (the dashed, red line) and without (the solid, green line) the vulnerability targeted contingent transfer scheme. As can be seen, there

\footnotetext{
${ }^{24}$ This analytical choice is primarily made for analytical convenience as under the triage policy developed in Section 3, the magnitude of cash transfer payments is itself uncertain, depending on the vagaries of the weather that dictate the residual budget left for such transfers. Clearly, we would expect cash transfers to discourage private accumulation (Hubbard et al. (1995) give an empirical example showing how meanstested social insurance programs discourage precautionary savings in the United States). By ignoring these disincentive effects, we are thus overerstating the possible efficacy of cash transfers.

${ }^{25}$ Recognize that risk is increasing in asset holdings because $\theta$ is a multiplicative shock and independent of $k$. Therefore, stochastic losses are greater when $k$ is larger.
} 
Figure 4: Nature's Tax Rates under Contingent Social Protection

(a) Expected Asset Losses

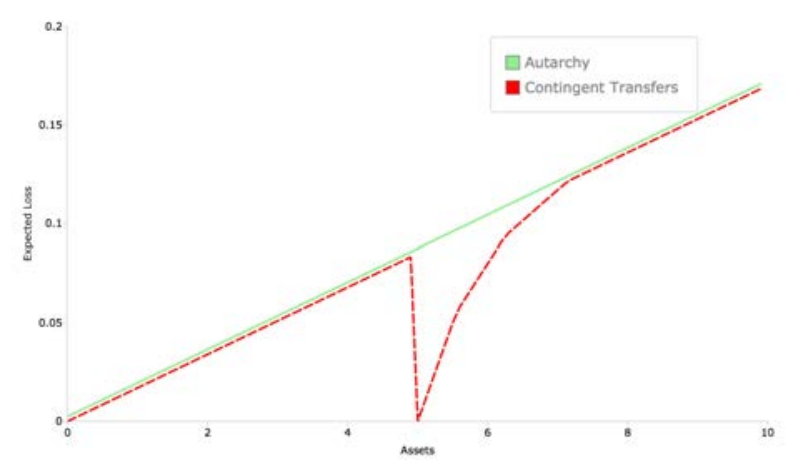

(b) Marginal Tax Rates

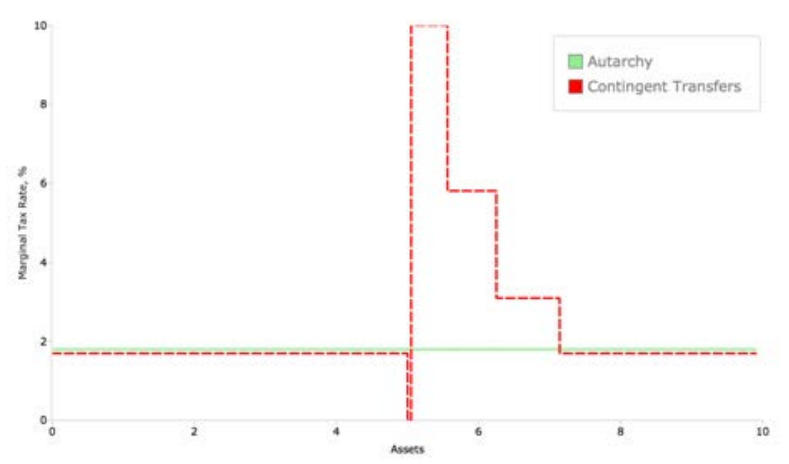

is zero chance of asset losses right at this threshold, and expected asset losses above the threshold will always keep the individual at or above $\tilde{k}$. When these contingent transfers of the vulnerability targeted social protection are anticipated, optimization problem 1 can be rewritten as follows:

$$
\max _{c_{j t}} \quad E_{\theta} \sum_{t=0}^{\infty} \beta^{t} u\left(c_{j t}\right)
$$

subject to:

$$
\begin{aligned}
& c_{j t} \leq k_{j t}+f\left(k_{j t}\right) \\
& f\left(\alpha_{j}, k_{j t}\right)=\alpha_{j} \max \left[f_{H}\left(k_{j t}\right), f_{L}\left(k_{j t}\right)\right] \\
& k_{j t+1}=\left\{\begin{array}{l}
\tilde{k}\left(\alpha_{j}\right) \text { if }\left(f\left(k_{j t}\right)-c_{j t}\right)+(1-\delta) k_{t}>\tilde{k}\left(\alpha_{j}\right) \text { and }\left(k_{j t}+\left(f\left(k_{j t}\right)-c_{j t}\right)\left(\theta_{j t+1}-\delta\right)<\tilde{k}(\right. \\
\left(k_{j t}+f\left(k_{j t}\right)-c_{j t}\right)\left(\theta_{j t+1}-\delta\right) \text { otherwise }
\end{array}\right. \\
& k_{j t} \geq 0
\end{aligned}
$$

This is the same as the problem specified in Section 2 except for the important change in the law of motion governing $k_{j t+1}$ now that households are aware of and respond to the contingent transfers. ${ }^{26}$

${ }^{26}$ The household problem at period $t$ can be represented in Bellman Equation form as:

$$
\begin{gathered}
V\left(k_{t}\right) \equiv \max _{i_{t}}\left\{u\left(f\left(\alpha, k_{t}\right)-i_{t}\right)+\beta E\left[V\left(k_{t+1} \mid k_{t}, i_{t}\right)\right]\right\} \\
\text { where } E\left[V\left(k_{t+1} \mid k_{t}, i_{t}\right)\right]=\int V\left(k_{t+1}\left(k_{t}, i_{t}, \theta_{t}, k_{g}, \delta\right)\right) d \Omega\left(\theta_{t}\right) \\
k_{t+1}\left(k_{t}, i_{t}, \theta_{t}, k_{g}, \delta\right)=\left\{\begin{array}{l}
k_{g} \text { if } i_{t}+(1-\delta) k_{t}>k_{g} \text { and } \theta_{t}\left[i_{t}+(1-\delta) k_{t}\right]<k_{g} \\
\theta_{t}\left[i_{t}+(1-\delta) k_{t}\right] \text { otherwise }
\end{array}\right.
\end{gathered}
$$


Figure 5: Ex Ante Impacts of Anticipated Social Protection

(b) Probability of Low Equilibrium under Social Protec-

(a) Probability of Low Equilibrium under Autarchy (\%)tion (\%)
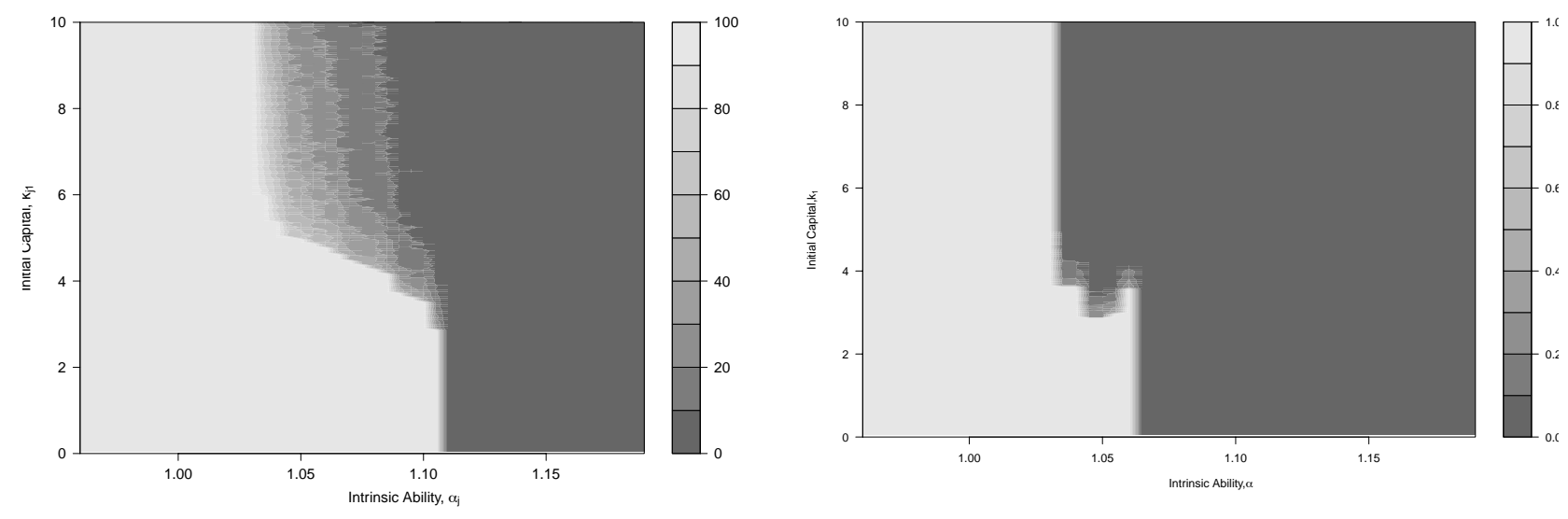

Figure 5 illustrates the impact of the anticipation of contingent transfers on the probability of chronic poverty. For ease of comparison, Figure 5a repeats those probability when these transfers are not anticipated. Comparing 5b with $5 \mathrm{a}$, we can see that substantially fewer endowment positions are likely to end up chronically poor. This additional accumulation induced by the presence of contingent transfers at the (autarchy) Micawber Frontier is precisely represents positive moral hazard.

While the vulnerability-targeted contingent transfers incentive upward mobility, they also have a discouraging effect on further accumulation that takes households beyond the safety of $\tilde{k}(\alpha)$ where assets are fully protected. A large swatch of middle ability agents end up in long-term equilibrium at exactly $\tilde{k}(\alpha)$. This behavior represents class negative moral hazard as the presence of the implicit insurance provided by the contingent transfer lead individuals to undertake behaviors that make contingent payments more likely.

Figure 4 illustrates the intuition for the emergence of this new insured outcome. Note that nature essentially acts as an unreliable tax collector in this model, probabilistically taking away some fraction of assets every period. Figure 4 a shows expected asset losses as a function of level of capital stock held. The solid (green) line shows these expected losses absent the contingent social protection scheme. Under the multiplicative risk specification, this is linear with a constant expected marginal tax rate of $1.7 \%$ (under the numerical assumptions used to analyze our model). This marginal tax rate is shown by the corresponding horizontal line in Figure 4b. 
Under the precisely targeted contingent transfer scheme, expected losses drop to exactly zero at $\tilde{k}(\alpha)$, as shown by the dashed line in Figure 4a. Beyond that asset level, expected losses begin to increase eventually becoming identical to expected losses absent this form of social protection. ${ }^{27}$ Figure $4 \mathrm{~b}$ shows the implied marginal tax rates under this scheme. As can be seen, under the discrete probability structure used to analyze the model, the marginal tax rate abruptly jumps from zero to $10 \%$, and then slowly decreases to the natural tax rate of $1.7 \%$ as capital stocks accumulate beyond the indemnity payment threshold. This sharp and discontinuous elimination of social protection as the individual moves away from the insured point $\tilde{k}(\alpha)$ discourages accumulation and leads to a class of agents who settle in at the new $\tilde{k}(\alpha)$ equilibrium.

\subsection{Using Index Insurance and Co-pays to Implement State of the World Contingent Social Protection}

Negative moral hazard and the attraction of $\tilde{k}(\alpha)$ as a new equilibrium reflects in part the extremely precise targeting of the contingent transfers (and sharp jump in marginal tax rates) that define the vulnerability-targeted social protection scheme. However, this kind of precise targeting is itself of dubious relevance in the real world where neither realized shocks, asset levels, nor individual skills are easy to observe. Together, these observations raise the question as to whether something akin to contingent social transfers can be implemented using a market-based microinsurance scheme. Index insurance, which delivers payouts to policy holders on the basis of a pre-determined index, could be particularly useful. Using index insurance poses four potential advantages:

1. Cheap to observe an index that signals shocks;

2. Rely on self-selection through the purchase of insurance, obviating the need to observe skill;

3. Requires a co-payment, reducing costs and changing incentives; and,

4. Because of cost reduction, it may eliminate the need for a precisely-targeted subsidy in order to avoid sharp discontinuities.

In a recent paper, Janzen et al. (2016) employ a dynamic model similar to that developed here, while ignoring skill heterogeneity. The analysis compares an autarchy scenario in which insurance is unavailable, and a targeted insurance subsidy scenario in which the government

\footnotetext{
${ }^{27}$ With bounded shocks, there will be a capital stock such that even largest shock cannot reduce assets to $\tilde{k}(\alpha)$, the level where contingent payments kick in.
} 
Figure 6: Costs of Alternative Social Protection Schemes

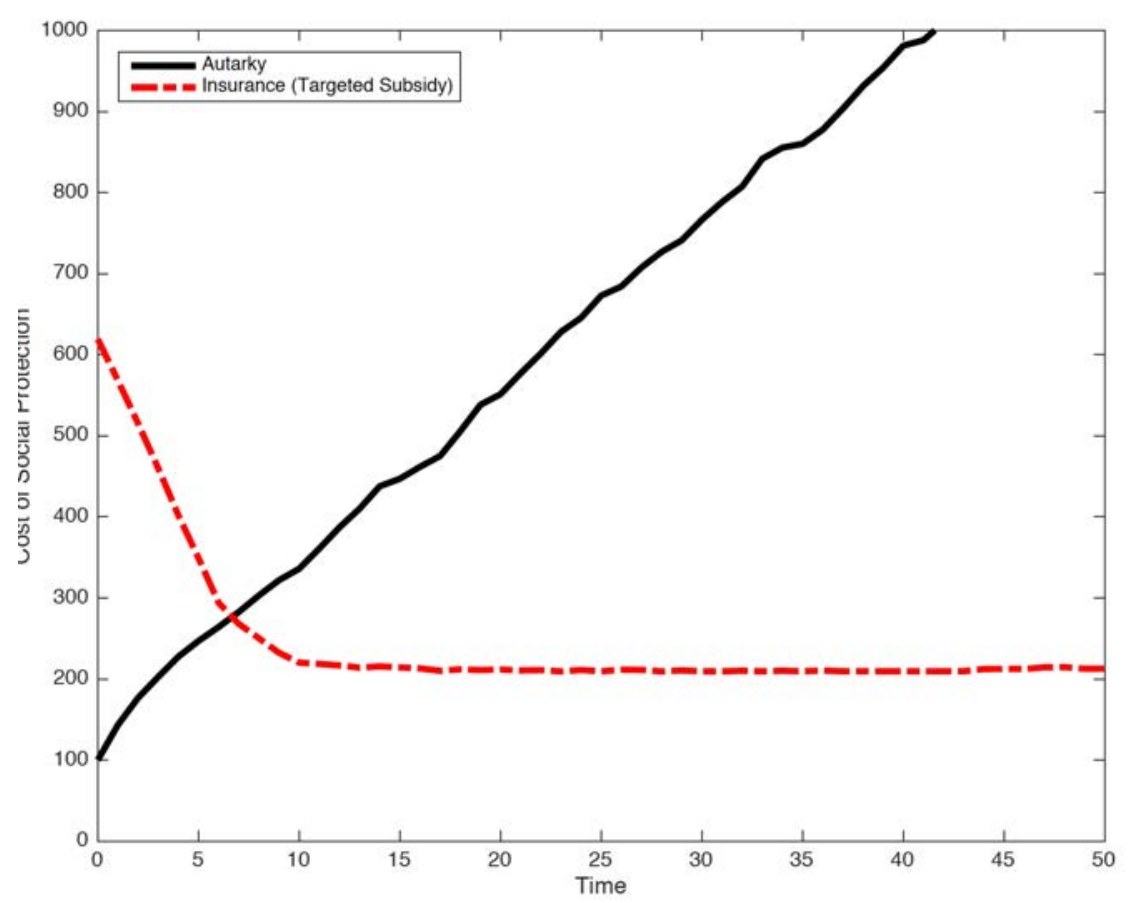

pays half of the commercial insurance premium (assuming a 20\% markup) for all households that hold assets less than the level required to generate an average income equal to $150 \%$ of the poverty line. In all cases, the simulation assumes that households behave optimally based on the price of insurance and the dynamic choice problem displayed above.

The Janzen et al. (2016) analysis shows a 50\% insurance subsidy (offered across the board to all but the wealthiest agents) can induce investment and upward mobility (positive moral hazard), but without the negative moral hazard seen in section 4.1 above. Importantly, they show that under the assumptions of their model, ${ }^{28}$ the total social protection budget (defined as funds for the insurance subsidy plus funds for cash transfers needed to close the poverty gap for all poor households) quickly becomes lower under a combined insurance-cash transfer scheme than under a pure cash transfer scheme. As shown in Figure 6, total costs are in fact higher in the short run under the hybrid scheme, but they become lower as the induced upward mobility eventually reduces the cost of cash transfers. Under their numerical assumptions, the present value of total social protection expenditures is $16 \%$ lower under the hybrid scheme.

\footnotetext{
${ }^{28}$ The parameters of the model deviate from those used in the other simulations in this paper. While the results are not directly comparable, the findings are still insightful. Notably, the Janzen et al. (2016) model must assume some level of basis risk (the difference between realized losses and the index). The model assumes relatively low basis risk. In practice, this is likely to overestimate the benefits of index insurance if basis risk is high.
} 
The feasibility of using index insurance to offer contingent protection has been extensively studied in the semi-arid regions of northern Kenya. Chantarat et al. (2012) and Mude et al. (2009) describe the initial contract design, while impact evaluation results on the ex post and ex ante effects of the insurance are reported in Jensen et al. (2014) and Janzen and Carter (2016). While demand issues remain a problem in practice (if not in theory!), the government of Kenya under its Kenya Livestock Insurance Program is currently trying to build on this insurance model to deliver contingent social protection.

\section{Conclusions}

This paper has put forward a dynamic stochastic model of a stylized poverty trap economy in which asset risk plays a major role and heterogeneity of individual ability creates two types of chronic poverty. Some people are chronically poor because their innate ability condemns them to a low standard of living. Others suffer unnecessary deprivation simply because they inherit insufficient productive capital to reach the critical asset or 'Micawber' frontier at which it becomes optimal to make the short-term sacrifices necessary to accumulate assets and (probabilisitically) escape chronic poverty.Each of these two poverty trap mechanisms invites a different policy response. When both types of chronic poverty co-exist, therefore, tradeoffs inevitably arise in developing cost-effective poverty reduction strategies.

Using this framework, we show that purely progressively-targeted social relief-such as cash transfers-can fall prey to an aid trap in which income support to the poorest of the poor crowds out asset protection for those of intermediate ability and wealth who are vulnerable to asset shocks and becoming themselves poor over time. Members of this latter group steadily fall into avoidable chronic poverty, adding to the pool of individuals suffering unnecessary deprivation and needing income support. As a result, while purely progressively-targeted social protection initially reduces the depth of poverty, the lot of the poor deteriorates over time due to increasing competition for limited social protection resources. Moreover, an unadorned, purely progressively-targeted system of social protection does not appreciably change the numbers of poor, nor does it enhance wealth accumulation, economic output or adoption rates of improved technologies.

We then show that a hybrid policy, which issues SWCTs to vulnerable-but-not-indigent households, eliminates unnecessary deprivation, empowers upward mobility and boosts growth through endogenous asset accumulation and adoption of improved technologies. While this hybrid policy still confronts important tradeoffs among different poor people and over time, this theoretical exercise establishes the potential gains to social protection that targets vulnerability, not just low current well-being, and in so doing creates economic multipliers. 
However, we show that despite these gains, household anticipation of SWCTs discourages some from accumulating assets beyond the range where they remain eligible for social protection transfers. A key question then becomes whether the balance between positive and negative moral hazard can be altered by changing the mode of delivering contingent transfers. Drawing on the work of Janzen et al. (2016), we show that imprecisely targeted partial subsidies for index insurance can achieve the benefits of SWCTs and strike a better balance between positive and negative moral hazard, encouraging upwardly mobility but not artificially braking it with means-tested cutoffs. While there are a plethora of challenges to implementing SWCTs via an insurance mechanism, in theory at least a hybrid social protection system that mixes insurance subsidies and cash transfers is a more cost-effective way to address chronic poverty in risk-prone regions like Northern Kenya. ${ }^{29}$

Ultimately, the key finding of this paper is that poverty traps characterized by multiple equilibria can have a pronounced effect on the performance and appropriate design of policies intended to stimulate poverty reduction, economic growth and uptake of improved production technologies. There are potentially large returns to developing and using knowledge about critical asset thresholds to target assistance to the vulnerable non-poor. The co-existence of populations facing different sorts of poverty traps, however, also raises unavoidable, thorny tradeoffs among distinct cohorts of the poor, as well as difficult intertemporal tradeoffs between current and future poverty reduction.

\footnotetext{
${ }^{29}$ At the time of this writing, this hybrid approach was just being implemented in Northern Kenya.
} 


\section{Appendix 1: Parameters and Other Details for Numerical Simulation}

This section provides additional detail on the formal model used to generate the results discussed in the main body of the paper.

The functional specification for the utility function $u(\cdot)$ is

$$
u\left(c_{t}\right)=\frac{c_{t}^{1-\sigma}-1}{1-\sigma}
$$

The probability density of $\theta_{t}$ is assumed to be:

$$
\text { density of } \theta_{t}=\left\{\begin{array}{l}
0.90 \text { if } \theta_{t}=1.0 \\
0.05 \text { if } \theta_{t}=0.9 \\
0.03 \text { if } \theta_{t}=0.8 \\
0.02 \text { if } \theta_{t}=0.7
\end{array}\right.
$$

The other structural parameter values are assumed as follows: $\sigma=1.5, \delta=0.08, \beta=0.95$, $\gamma_{L}=0.3, \gamma_{H}=0.45, E=0.45$.

We discretize continuous variables $k$ and $\alpha$ as follows: $k=\{0.05,0.10, \ldots, 15.00\}$ and $\alpha=\{0.960,0.965, \ldots, 1.190\}$.

For the simulation of the stylized economy of 300 individuals we draw $\alpha$ from $\mathrm{N}\left(1.070,0.055^{2}\right)$, with the mean and variance chosen so that ex ante proportion of low, middle, and high type individuals (defined relative to the stochastic Micawber Frontier) would be 25\%, 50\%, and $25 \%$, respectively. We draw $k_{1}$ from Uniform $[0.1,10.0]$ and assume that $k_{1}$ and $\alpha$ are statistically independent from each other.

We specify poverty line as follows. The asset level which generates income exactly equal to the poverty line satisfies the following equation:

$$
y_{p}=f\left(\alpha, k_{p}\right)
$$

where $y_{p}$ is income-based poverty line. That asset level obviously depends on $\alpha$ and we denote it by $k_{p}(\alpha)$. We assume that an intermediate ability individual would fall below the income poverty line if he used the low technology and thus set poverty line by $k_{p}(\alpha=1.070)=2.8$ and thus $y_{p}=1.46$. 


\section{References}

Azariadis, Costas, and John Stachurski (2005) 'Poverty traps.' In Handbook of Economic Growth, ed. Philippe Aghion and Steven N. Durlauf, vol. 1, Part A (Elsevier) chapter 5, pp. $295-384$

Banerjee, A., E. Duflo, N. Goldberg, D. Karlan, R. Osei, W.Pariente, J. Shapiro, B. Thuysbaert, and C. Udry. (2015) 'A multifaceted program causes lasting progress for the very poor: Evidence from six countries.' Science

Barrett, Christopher B., and Michael R. Carter (2013) 'The economics of poverty traps and persistent poverty: Policy and empirical implications.' Journal of Development Studies

Barrett, Christopher B., Michael R. Carter, and Munenobu Ikegami (2013) 'Poverty traps and social protection'

Barrett, Christopher B., Paswel Phiri Marenya, John McPeak, Bart Minten, Frank Place, Jean Claude Randrianarisoa, Jhon Rasambainarivo, and Justine Wangila (2006) 'Welfare dynamics in rural kenya and madagascar.' Journal of Development Studies 42(2), 248-277

Bastagli, Francesca, Jessica Hagen-Zanker, Luke Harman, Valentina Barca, Georgina Sturge, and Tanja Schmidt (2016) 'ash transfers: what does the evidence say?' Technical Report, Overseas Development Institute

Buera, Francisco J. (2009) 'A dynamic model of entrepreneurship with borrowing constraints: theory and evidence.' Annals of Finance 5(3-4), 443-464

Calvo, Cesar, and Stefan Dercon (2009) 'Chronic poverty and all that: The measurement of poverty over time.' In Poverty Dynamics: Interdisciplinary Perspectives, ed. Tony Addison, David Hulme, and Ravi Kanbur (Oxford University Press) chapter 2

Carter, Michael R., and Christopher B. Barrett (2006) 'The economics of poverty traps and persistent poverty: An asset-based approach.' Journal of Development Studies 42(2), 178199

Carter, Michael R., and Munenobu Ikegami (2009) 'Looking forward: Theory-based measures of chronic poverty and vulnerability.' In Poverty Dynamics: Interdisciplinary Perspectives, ed. Tony Addison, David Hulme, and Ravi Kanbur (Oxford University Press) chapter 6

Carter, Michael R., and Sarah A. Janzen (2015) 'Social protection in the face of climate change: Targeting principles and financing mechanisms.' World Bank Policy Research Paper 7476 
Chantarat, Sommarat, Andrew G. Mude, Christopher B. Barrett, and Michael R. Carter (2012) 'Designing index-based livestock insurance for managing asset risk in northern kenya.' Journal of Risk and Insurance pp. no-no

Deaton, Angus (1991) 'Saving and liquidity constraints.' Econometrica

Elbers, Chris, and Jan Willem Gunning (2005) 'Growth and risk: Analytical and empirical issues.' mimeo.

Gertler, Paul J, Sebastian W Martinez, and Marta Rubio-Codina (2012) 'Investing cash transfers to raise long-term living standards.' American Economic Journal: Applied Economics 4(1), 164-192

Ghatak, Maitreesh (2015) 'Theories of poverty traps and anti-poverty policies.' World Bank Economic Review pp. 1-29

Hubbard, R. Glenn, Jonathan Skinner, and Stephen P. Zeldes (1995) 'Precautionary saving and social insurance.' Journal of Political Economy 103(2), 360-399

Hurrell, Alex, and Rachel Sabates-Wheeler (2013a) 'Kenya hunger safety net programme monitoring and evaluation component: quantitative impact evaluation final report: 2009 to 2012.' Technical Report, Oxford Policy Management, June

_ (2013b) 'Kenya hunger safety net programme monitoring and evaluation component: quantitative impact evaluation final report: 2009 to 2012.' Technical Report, Oxford Policy Management

Janzen, Sarah A., and Michael R. Carter (2016) 'After the drought: The impact of microinsurance on consumption smoothing and asset protection.' NBER Working Paper

Janzen, Sarah A., Michael R. Carter, and Munenobu Ikegami (2016) 'Asset insurance markets and chronic poverty'

Jensen, Nathaniel D., Christopher B. Barrett, and Andrew G. Mude (2014) 'Index insurance and cash transfers: A comparative analysis from northern kenya'

Kraay, Aart, and David McKenzie (2014) 'Do poverty traps exists? assessing the evidence.' Journal of Economic Perspectives 28(3), 127-148

Kray, A., and D. McKenize (2014) 'Do poverty traps exist? assessing the evidence.' Journal of Economic Perspectives 28(3), 127-148 
Krishna, Anirudh (2006) 'Pathways out of and into poverty in 36 villages of andhra pradesh, india.' World Development 34(2), 271-288

Kwak, S, and S Smith (2013) 'Regional agricultural endowments and shifts of poverty trap equilibria: Evidence from ethiopian panel data.' Journal of Development Studies

Loury, Glenn C. (1981) 'Intergenerational transfers and the distribution of earnings.' Econometrica 49(4), 843-867

Lybbert, Travis J., Christopher B. Barrett, Solomon Desta, and D. Layne Coppock (2004) 'Stochastic wealth dynamics and risk management among a poor population.' The Economic Journal 114(498), 750-777

Maldonado, Jorge Higinio, Rocío del Pilar Moreno-Sánchez, John Alexander Gómez, and Viviana León Jurado, eds (2016) Protección, Producción, Promoción: Explorando Sinergias entre Protección Social y Fomento Productivo Rural en América Latina (Ediciones UNIANDES)

McPeak, John, and Christopher B. Barrett (2001) 'Differential risk exposure and stochastic poverty traps among east african pastoralists.' American Journal of Agricultural Economics 83, 674-679

Mude, Andrew G., Sommarat Chantarat, Christopher B. Barrett, Michael R. Carter, Munenobu Ikegami, and John McPeak (2009) 'Insuring against drought-related livestock mortality: Piloting index based livestock insurance in northern kenya.' Working Paper, International Livestock Research Institute, Nairobi, Kenya

Nashold, Felix (2013) 'Welfare dynamics in pakistan and ethiopia - does the estimation method matter?' Journal of Development Studies

Santos, Paulo, and Christopher B. Barrett (2011) 'Persistent poverty and informal credit.' Journal of Development Economics 96(2), 337-347

_ (2016) 'Heterogeneous wealth dynamics: On the roles of risk and ability.' working paper, Cornell University

Skiba, A. K. (1978) 'Optimal growth with a convex-concave production function.' Econometrica 46(3), 527-539. pdf copy

Subramanian, Shankar, and Angus Deaton (1996) 'The demand for food and calories.' Journal of Political Economy 104(1), 133-162 